\title{
Behaviour of Wheat and Rye Genome Chromosomes in Triticale-A Review
}

\author{
V.R. K. Reddy, Renu Edwin and C. P. Suganthi \\ Cytogenetics Laboratory, Department of Botany, Bharathiar \\ University, Coimbatore-64l 046, India
}

Accepted October 12, 1992

The chromosome behaviour of wheat and rye genomes were discussed in triticale with reference to cytological and other characters. Rye chromosomes show preferential involvement in meiotic disturbances and were attributed to differential meiotic duration, genome allocycly and to the amount of heterochromatin. Both wheat and rye chromosomes influence each other homologous and homoeologous pairing either through increase in the dose of genome or individual chromosomes or genes. Cytoplasmic-nuclear interactions also regulate the meiotic chromosome pairing of wheat and rye chromosomes and other characters in triticale. Chromosome substitutions and translocations involving $\mathrm{A}, \mathrm{B}, \mathrm{D}$ and $\mathrm{R}$-genome chromosomes occur in most of the triticales. Variability in the expression of individual genes of wheat and rye noticed in triticale.

The degree of chromosome pairing in triticale were influenced by both wheat and rye genomes. In wheat-rye combination, rye and wheat genomes influence both homologous and homoeologous pairing, they also compete each other in nucleolus formation. Rye chromosomes preferentially involved in meiotic irregularities and its genes are either supressed or partially expressed in triticales which may be due to pressure asserted by wheat genome or its cytoplasm. In the following review, the behaviour of wheat and rye genomes with reference to several cytological and other features in triticale are discussed.

\section{Chromosome pairing}

(i) Dosage Effect-Wheat-wheat and wheat-rye homoeologous pairing increased with increase in the dose of rye genome chromosomes in triticale-rye hybrids. A reduction in the dosage of wheat genomes in wheat-rye combinations, increases the probability of wheat-rye homoeologous pairing. An increase in the dosage of rye genome, increases the level of homoeologous pairing between wheat chromosomes. High level of homoeologous pairing noticed due to increase in the dosage of homoeologous group 3 chromosomes (3B and $3 \mathrm{R}$ ). Hybrids with double doses of $5 \mathrm{R}$ causes high degree of homoeologous pairing perhaps by suppressing the effect of $p h$ allele of 5B. Bernard and Bernard (1985) noticed that the highest number of rye chromosomes were involved in homoeologous pairing $(1.6 / \mathrm{pmc})$ in ABDR hybrids nullisomic for $5 \mathrm{~B}$, while the frequency of homoeologous pairing in ABDRR hybrids was similar in the presence or absence of $5 \mathrm{~B}$, suggesting that dosage effect of the rye genome in promoting homoeologous pairing. A correlation between chromosome instability and the wheat phl gene dosage has been detected in wheat $\times$ rye and barley $\times$ wheat $F_{1}$ hybrids (Mello-Sampayo et al. 1988, Vieira et al. 1991). In hybrids derived from crosses between triticale $(8 x, 6 x, 4 x)$ and diploid rye (Figs. 1-2), it was noticed that an increase in the relative proportion of wheat chromosomes in the hybrids had a suppression effect on homologous as well as homoeologous pairing of rye and relative increase in rye complement promoted homoeologous pairing between wheat chromosomes. Similarly, in the hybrids ABRRR, ABRR, the wheat comple- 

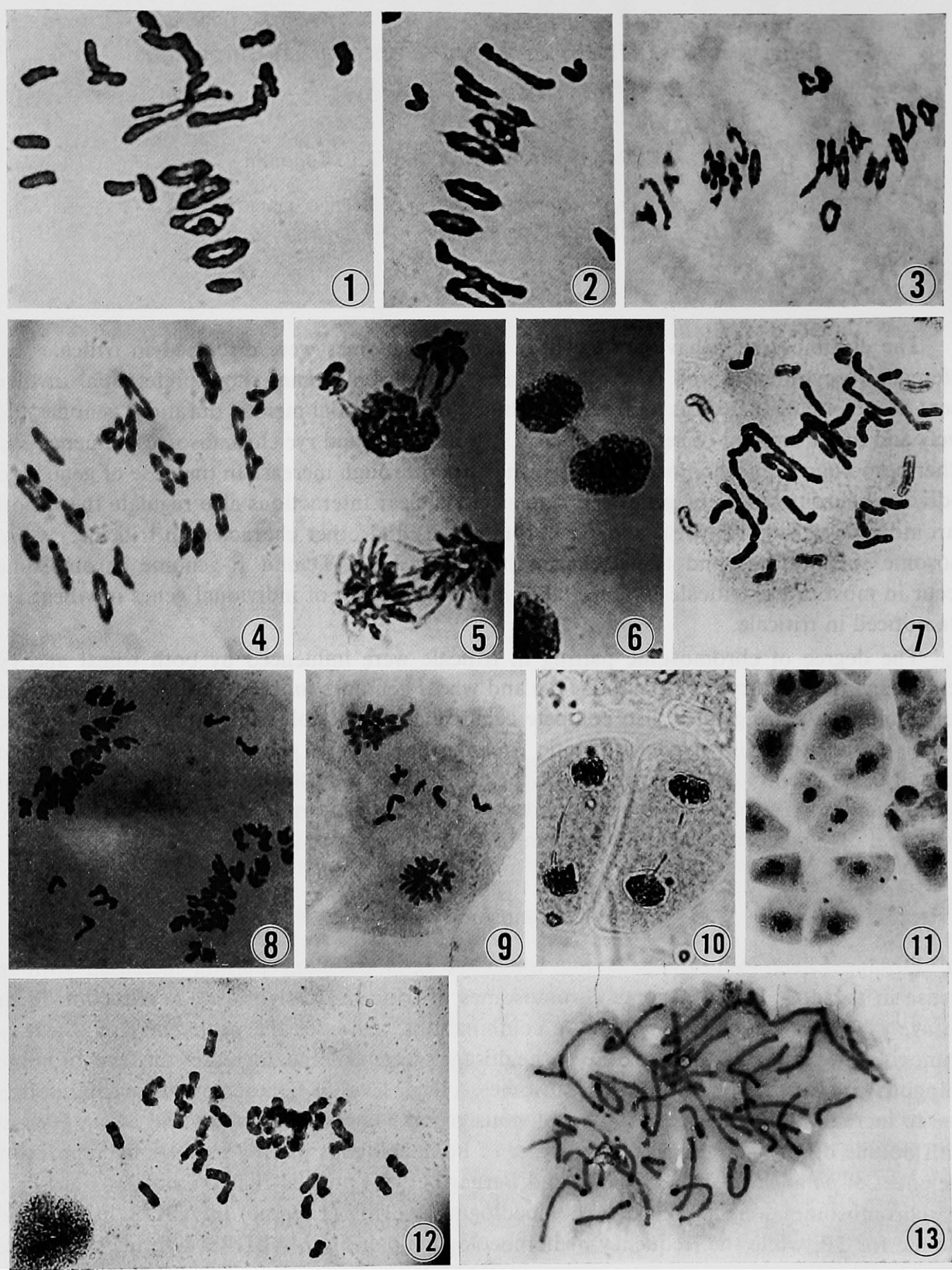

(13)

Figs. $1-13.1,7^{\prime \prime}+14^{\prime}$ in $6 x$ triticale $\times 2 x$ rye hybrids. $2,9^{\prime \prime}+3^{\prime}$ in $4 x$ triticale $\times 2 x$ rye hybrids. $3-4$, Meiotic metaphase of $6 x$ triticale $(6 x=42)$. 5-6, Mitotic anaphase bridges in $6 x$ triticale. 7-12, Meiotic irregularities in $6 x$ triticale. 7, Univalents. 8, Dividing univalents. 9, Laggards. 10, Anaphase bridges. 11, Micronuclei. 12, Asynaptic cell with a single ring bivalent. 13, Giemsa C-banding of somatic metaphase chromosomes in $6 x$ triticale showing substitutions of rye chromosomes. 
ment $A B$, has shown to reduced the homologous pairing between rye chromosomes relative to that found in triploid (RRR) and diploid (RR), and the presence of rye chromosomes in these hybrids increase the homoeologous pairing between the chromosomes of wheat (AB) (Naranojo et al. 1979).

(ii) Role of Individual Chromosomes and Genes-Certain rye chromosomes eg. 2R and 5R has a promotional effect and chromosome $4 \mathrm{R}$ has a suppression effect on homoeologous pairing in triticale. It was also noticed that a single dose of the short arms of rye chromosomes $7 \mathrm{R} /$ $4 R$ and $5 R$ as well as $1 R$ have an adverse effect on chiasma formation in hybrids between the varieties of Chinese Spring and Holdfast. Miller and Riley (1972) suggested that the activity of rye chromosome arm $5 \mathrm{RL}$ is similar to that of $5 \mathrm{BL}$ of wheat in preventing homoeologous pairing. Orellana et al. (1984) noticed that the strongest diminution of wheat pairing (75\%) was produced by $5 \mathrm{R}$ of rye and the weakest diminution of wheat pairing $(1 \%)$ was produced by $3 \mathbf{R}$. Where as the diminution of rye chromosome pairing produced by wheat chromosomes ranges from 6.9 to $48.4 \%$.

(iii) Interaction of Genomes-An increase in chromosome pairing in certain wheat $\times$ rye hybrids may not only the result of specific effects of chromosomes and genes of wheat and rye, the new interaction of genetic systems of wheat and rye also influence chromosome pairing (Stefanowska 1988). Galindo and Jouve (1989) observed a strong negative intergenomic interaction between the rye and wheat genomes in triticale mainly affecting the meiotic pairing of rye chromosomes. The role of wheat chromosome $1 \mathrm{~B}$ in the interaction with rye genome has also been emphasized since a higher degree of meiotic stability in monosomic 'Rosner' and low degree of meiotic instability in 'Rosner' trisomic for $1 \mathrm{~B}$.

(iv) Cytoplasmic-Nuclear Interactions-Hexaploid triticales containing the extracted AABB component and the cytoplasm from hexaploid wheat had an improvement in meiotic stability (Thomas and Kaltsikes 1972). Rye cytoplasm in tetraploid triticales did not increase the meiotic stability of rye chromosomes (Melz and Schlegel 1987). Triticale lines some of which contained hexaploid wheat cytoplasm and others tetraploid wheat cytoplasm had a significantly lower number of univalents per cell and improved fertility. A 2R/2D substitution in triticale gave high seed fertility in aestivum cytoplasm over cereal cytoplasm (Yasumuro et al. 1987).

(v) Role of Heterochromatin-In both hexaploid and octoploid triticales and in wheat-rye addition lines, the rye univalents were correlated with the presence of telomeric heterochromatin (Reddy 1988a). Telomeric heterochromatin of rye effects the chiasma position in rye and univalent formation in the wheat-rye amphiploid and in wheat (Gupta and Reddy 1991). A strong correlation was found between the increased heterochromatin content and pairing failure (Reddy 1990). Rye chromosomes with only one telomeric band were present as rod bivalents (Fig. 3) paired in the non-heterochromatic ends and those with telomeric bands on both the arms were found more frequently as univalents. A number of studies also attributed the variation in chromosome pairing and chiasma frequency to the distribution of heterochromatin of rye chromosomes. In both diploid and tetraploid rye, chromosome $2 \mathrm{R}$, with prominent bands on both the telomeres was present as univalent in highest frequency $(43.82 \%)$ in comparision to 3R (7.69\%) with small bands (Lukaszewski and Gustafson 1986). Further it was shown that in advanced hexaploid triticale lines with homozygous deletions of telomeric heterochromatin on one or more of rye chromosomes $1 \mathrm{R}, 3 \mathrm{R}, 4 \mathrm{R}$ and $5 \mathrm{R}$ were associated with improved meiotic stability compared to that found in controls (Fig. 4). Huelgenhof et al. (1988) noticed pairing stability in homozygous deficient lines with a correlation between percentage of heterochromatin with mean univalent frequency. Effect of rye heterochromatin on pairing in wheat is also reported recently (Bernardo et al. 1988) and the influence being more pronounced for large arms than for the short ones.

The presence of extra homologous for $1 \mathrm{~A}$ or $1 \mathrm{D}$ or $2 \mathrm{~A}$ or $2 \mathrm{~B}$ or $3 \mathrm{~B}$ increased non-homo- 
logous pairing and the extra homologue for $7 \mathrm{~A}$ decreased non-homologous pairing. Darvey and Larter (1973) found that monosomic or trisomic condition of chromosome 1B leads to better or worse meiotic stability respectively. Bernard and Bernard (1985) analysed the role of D-genome participation in homoelogous pairing in different hybrid combinations involving triticales at different ploidy level and it was concluded that D-genome chromosome participation in homoeologous pairing is less than one.

Many cases of genes influencing meiosis has been reported. Lelley (1975) based on lack of correlation between chiasma frequency and univalents within the plant and a significant correlation between the plants, suggested that rye chromosome pairing in triticale is under the control of polygenes and it was also suggested that genes for asynapsis in rye genome can reduce chromosome pairing in triticale. Schlegel and Weryszko (1979) identified several alleles in rye that effect homoeologous pairing between wheat and rye chromosomes. In an analysis of different tetraploid triticales, Lukaszewski and Gustafson (1986) noticed variation in rye pairing frequencies in $4 x$ triticalse corresponded to those found in inbred ryes, indicating that the tetraploid lines differed from each other in the rye genes controlling chromosome pairing.

\section{Nucleolar activity}

In octoploid triticales, wheat chromosomes $1 \mathrm{~B}$ and $6 \mathrm{~B}$ and rye chromosome $1 \mathrm{R}$ and also $6 \mathrm{R}$ taking part in nucleolus formation. Whereas, in hexaploid triticales, only the wheat chromosomes $1 \mathrm{~B}$ and $6 \mathrm{~B}$ participate in nucleolus formation while the activity of rye NOR chromosomes was suppressed (Lukaszewski and Gustafson 1986). Similarly, the activity of 5D of wheat was also shown suppressed in $6 x$ forms. However, in octoploid triticale, there is strong evidence to show that $5 \mathrm{D}$ is activated by rye genome (Rangel-Figuriedo et al. 1985). Changes in the dosage of chromosomes $1 \mathrm{~B}$ and $6 \mathrm{~B}$ had a strong influence on nucleolar frequencies in triticale (Thomas and Kaltsikes 1983). In trigeneric hybrids involving triticale and tritordeum, while both wheat and barley chromosomes were involved in the nucleolus formation, rye chromosome activity was suppressed (Feranandez-Escobar and Martin 1985). Petrovic et al. (1988) noticed that in most of the Yugoslavian wheats having 1B/1R substitution and/or translocations the NOR of rye was completely reduced. Recently, using specific DNA probes isolated from the rye spacer region it has been shown that the rye rDNA retains some potential for NOR activity when placed in a wheat background (Appeals et al. 1986). However, the level of rDNA appears to depend on the presence or absence of wheat chromosome 1B and/or 6B. Capesius and Appels (1989) has shown that in tetraploid triticales, the NOR activity of rye is suppressed by NOR of wheat and the suppression is derectly related to suppression of RNA transcription of rye and thus a reduction in rRNA synthesis. The results discussed above, therefore, provide evidence for the existance of an activation-inhibition system of genetic control of NOR activity, acting at the level of interaction between chromosomes and between genomes.

\section{Aneuploidy}

Cytologically observable features in triticale are the presence of mitotic and meiotic irregularities, gametes with unbalanced chromosome number and plants with aneuploid chromosome number, (Figs. 5-11). Differential duration of cell cycles of wheat and rye, disturbances at premeiotic mitosis could account for many of the disturbances. Asynapsis and/or desynapasis were also attributed for these distubances (Fig. 12). Neocentric activity of some rye chromosomes also seems to play a role in meiotic disturbances in triticale. The effect of 
'Hybrid desynapasis' for pairing instability and aneuploid formation in intervarietal hybrids of wheat, also seems to be moderately expressed in triticale.

It was earlier proposed that the wheat and rye genomes in triticale behave autonomously i. e. genome allocycly, which may well be a factor in octoploid triticale, since the univalents formed are mainly those of rye. However, genome allocycly cannot explain the presence of occuassional wheat chromosomes as univalents in octoploid triticales, nor the general presence of univalent wheat chromosome in hexaploid triticales. Another theory based on the assumption that the forced homozygosity of allogamous rye chromosomes may be the genetic cause of univalent formation, since, reduced chiasma frequency is available in inbred ryes.

In hexaploid triticale, chromosome $1 \mathrm{~B}$ tends to be involved in aneuploidy more frequently $(34 \%)$ than any other chromosomes $(2 \mathrm{R}-9 \%)$ the remaining chromosomes were involved only a maximum of $5 \%$. It was observed that the presence of chromosome $1 \mathrm{~B}$ results in better or worse meiotic stability depending on whether or not it is in the monosomic or trisomic condition, respectively (Darvey and Larter 1973). This perhaps due to natural selection pressure towards the elimination of $1 \mathrm{~B}$ and/or $6 \mathrm{~B}$. Several high yielding wheats, in fact contain either $1 \mathrm{~B} / 1 \mathrm{R}$ substitution or $1 \mathrm{~B} / 1 \mathrm{R}$ translocation supports this hypothesis.

\section{Substitutions and translocations}

Most of the present-day $6 x$ triticales resulted from the crosses either with $8 x$ triticales or with $6 x$ wheats, contain substitutions or translocations of D-genome chromosomes for those of R, A and B-genomes. This was possible due to frequent failure or reduced homologous chromosome pairing, as well as homoelogous pairing in the hybrids. Substitutions of Dgenome chromosome for R-genome chromosomes (Fig. 13) are well established (Reddy 1988b, 1992a, Gustafson et al. 1989) and substitutioos of D-genome chromosomes for A- or B-genome chromosomes reported recently (Lukaszewski 1988, Hohmann and Krolow 1991). The replacement of R-genome chromosomes by $\mathrm{D}$-genome chromosomes are mainly controlled by the genes present on D-genome chromosomes and the ability for the D-genome chromosome to compensate for rye chromosomes. Translocations between $\mathrm{B}, \mathrm{D}$ - and R-genome resulted due to pairing failure of $\mathrm{B}, \mathrm{D}$ - and R-genome chromosomes in the derived $\mathrm{F}_{1}$ hybrid of triticale and wheat, as a univalents both $\mathrm{R}$ and $\mathrm{B}, \mathrm{D}$ chromosomes have a tendency to misdivide. The resulting telocentric chromosome often fuse, forming new arm combinations. Both misdivision and fusion frequencies appear to be chromosome specific, and to be affected both by genotype and environment. The possibility of translocations among wheat chromosomes in triticale cannot be ruled out, however, no serious attempts were made to identify them, however, Schlegel and Schlegel (1989) listed the available 270 wheat intervarietal translocations involving A, B and D-genome chromosomes.

\section{Expressivety of genes}

Triticale, since carrying genes from both the wheat and rye genomes, it possesses chracters from both the parents regardless of its nature of function. Ability to grow in sandy soils, longer spikes, winter hardiness, disease resistance from rye; good nutritional quality, early maturity, insensitivity for day length from wheat are some examples in this regard, however, the genes responsible for plant height and grain yield in rye and/or wheat seems not effective in triticale. Oettler et al. (1991) has shown that in hexaploid triticales, all the characters which affects the fertility are mainly controlled by rye genes while wheat genes controls largely the vegetative development. The alluminium tolerance from rye is poorly expressed in triticale this is because of tolerance system from rye is modified by suppressor genes of wheat 
(Gustafson et al. 1991). Similarly, many characters governed by single genes in rye which do not often segregate in single gene rations in triticale (eg. hairy neck). Many of the very good genes for disease resistance present in either of the parental species are never fully expressed in triticale. In some cases, triticale susceptible to diseases for which wheat or rye parents are resistant. The amount of acid phosphatase enzymes produced by the genes in triticale, and responsible of kernel shrivelling is lower than either of the parents and the factors responsible for this phenomena is still not yet identified. Changes in rye telomeric heterochromatin content was noticed in several triticale and a number of factors suggested for this variation (Reddy 1988a, 1989, 1990) but its final effect appears to be in gene modulation (Gupta and Reddy 1991). The reasons for the erratic expression of the genes are not clear, but obviously there are many complex reactions occuring between the genes of wheat and rye.

Influence of environmental factors on the expression of wheat and rye genomes

Increase in temperature shortened the meiotic cycle in wheat and rye and leads to many meiotic irregularities (Reddy 1992b). There are also indications that the environments can influence chromosome pairing and chiasma frequency in wheat and in triticale (Naranjo et al. 1989). Queiroz et al. (1991) identified low temperature stabilization genes Ltp1 in 5DL, Ltp2 in 5AS, Ltp3 in 5BS and Ltr (low temperature recombination gene) in 5DS. UV radiatioo may be one of the factors responsible for heterochromatin deletions in many CIMMYT triticale lines grown at high altitudes (Reddy 1988a). Breeder selection has been shown to either increase or decrease the heterochromatin content from rye genome in each generation for establishment of a balanced nucleotype of triticale (Jouve et al. 1988). The karyotype stabilization of $\mathrm{A}$ and $\mathrm{B}$ chromosomes in tetraploid triticale and their selective advantage is also seems to be determined by genotype-environment interactions.

\section{Conclusion}

The genetics and cytogenetics of triticale are very closely associated with the interactions that occur between the genomes of wheat and rye. In most cases, genes from rye, when present in triticale background, do not express themselves in a manner similar to that observed in diploid rye. This is seen in characters governed by single genes which do not often segreagate in single gene ratios when in a triticale. The rye chromosomes can even alter chromosome morphology when in a triticale background. In addition, pairing frequencies and heterochromatin content of rye chromosome can also change when present in a wheat background. From the above it is clear that the genetics and cytogenetics of triticale are very complex and continue to present challenges to the researcher.

\section{Acknowledgements}

Senior author V R K R is greatful to UGC, New Delhi for financial assistance in the form of a minor research project.

\section{References}

Appels, R., Mora, B. and Gustafson, J. P. 1986. The structure of DNA from rye (Secale cereale) NOR-1R locus and its behaviour in wheat backgrounds. Can J. Genet. Cytol. 28: 673-685.

Bernard, M. and Bernard, S. 1985 . Meiotic pairing in hybrids between tetroploid triticale and related species: new elements concerning the chromosome constitution of tetraploid triticale. Theor. Appl. Genet. 70: $390-399$. 
Bernado, A., Garcia, M. and Jouve, N. 1988. The effect of Secale cereale L. heterochromatin on wheat chromosome pairing. Genetica 77: 89-95.

Capesius, I. and Appels, R. 1989. The direct measurement of ribosomal gene activity in wheat-rye hybrids. Genome 32: 343-346.

Darvey, N. L. and Larter, E. N. 1973. Monosomic segregation in hexaploid triticale cv. Rosner. European Wheat Aneuploid News Letter 4: 70.

Feranandez-Escobar, J. and Martin, A. 1985. Morphology, cytology and fertility of trigeneric hybrid from triticale $\times$ tritordeum. Z. Pflanzenzuct. 95: 311-318.

Galindo, C. and Jouve, N. 1989. C-banding in meiosis: an approach to the study of wheat and rye genome interactions in triticale. Genome 32: 1074-1078.

Gupta, P. K. and Reddy, V.R. K. 1991. Cytogenetics of triticale-A man made cereal. In: "Chromosome Engineering in Plants (Eds. P. K. Gupta and T. Tsuchiya), Elsevier Science Publishers, The Netherlands, part A, pp. 335-359.

Gustafson, J. P., Dille, J. E. and Skovmad. B. 1989. Wheat subsititutions in hexaploid triticale. Plant Breed. 102: 109-112.

-, Bushuck W. and Dera, A. R. 1981. Triticale: Production and utilization. In: Handbook of Cereal Science and Technology (Eds. K. J. Lorenz and K. Kulp) Marcel Dekker Inc. New York, pp. 373-399.

Hohmann, U, and Krolow, K. D. 1991. Introduction of D-genome chromosomes from Aegilops squarrosa L. into tetraploid triticale (AB) (AB) RR $(2 n=28)$. Thero. Appl. Genet. 82: 777-783.

Huelgenhof, E., Pershina, L. and Schlegel, R. 1988. The contribution of heterochromatin variations and chromosome replacements to breeding research of hexaploid triticale. Tag. Ber. Akad. LandwirtschWiss DDR. 266 S. 95-103.

Jouve, N., Galindo, C., Mesta, M., Diaz, F., Albella, B., Garcia, P. and Soler, C. 1989. Changes in triticale heterochromatin visualized by C-banding. Genome 32: 735-742.

Lelley, T. 1975. Genetic control of pairing of rye chromosomes in triticale. Z. Pflanzenzucht. 75: 24-29.

Lukaszewski, A. J. 1988. Chromosome constitution of hexaploid triticale lines in the recent international yield trials. Plant Breed. 100: 268-272.

Lukaszewski, A and Gustafson, J. P. 1986. Cytogenetics of triticale. Plant Breed. Rey. 5: 41-93.

Mello-Sampayo, T., Viegas, W. and Vieira, R. 1988. Chromosome aberrations in $F_{1}$ hybrids Triticum aestivum Secale cereale in the absence of ph 1 gene. Broteria Genet. 9: 167-173.

Miller, T. E. and Riley, R. 1972. Meiotic chromosome pairing in wheat-rye combinations. Genetica Iber. 24: $1-10$.

Melz, G. and Schlegel, R. 1987. Production and cytogenetic analysis of a rye-cytoplasmic tetraploid triticale. Plant Breed. 98: 200-204.

Naranio, T., Fernandez-Rueda, P., Goicoechea, P. G., Roca, A. and Giraldez, R. 1989. Homoelogous pairing and recombination between the long arms of group 1 chromosomes in wheat $\times$ rye hybrids. Genome 32: 293-301.

-, Lacadena, J. R. and Giraldez, R. 1979. Interaction between wheat and rye genomes on homologous and homoeologous pairing. Z. Pflanzenzucht. 82: 289-305.

Oettler, G., Wehmann, F. and Utz. H. F. 1991. Influence of wheat and rye parents on agronomic characters in primary hexaploid and octoploid triticale. Theor. Appl. Genet. 81: 401-405.

Orellana, J., Ceremeno, M. C. and Lacadena, J.R. 1984. Meiotic pairing in wheat-rye addition and substitution lines. Can. J. Genet Cytol. 26: 25-33.

Petrovic, S., Dera, A. R. and Gustafson, J. P. 1988. Rye chromatin variation in Yogoslavian wheats. Plant Breed. 100: 83-87.

Queiroz, A., Mello-Sampayo, T. and Viegas, W. S. 1991. Identification of low temperature stabilizing genes, controlling chromosome synapsis of recombination, in short arms of chromosomes from the homoeologous group 5 of Triticum aestivum. Heriditas 115: 37-41.

Rangel-Figuriedo, T., Guedes-Pinto, H. and Mello-Sempayo, T. 1985. Nucleolar organizer activity in triticales of different genome constitution. Proc. EUCARPIA Triticate Symp., Cermont-Ferrand, France, pp. $65-76$.

Reddy, V. R. K. 1988a. Effects of rye telomeric heterochromatin in triticale. Crop. Res. 1: 6-15.

- 1988b. Rye chromosome composition and kernel characters in different hexaploid triticales. Indian J. Genet 48: 289-293.

- 1989. Heterochromatin of rye and triticale-repetitive sequence. Curr. Sci. 58: 1211-1213.

- 1990. Present status and future prospects of triticale improvement. J. Agric. Issues. 2(1\&2): 43-53.

- 1992a. Chromosome constitution in different haxaploid triticales. Adv. Pl. Sci. 5(2): 524-530.

- 1992b. Role of temperature on meiotic stability in barley triticale and wheat. Crop Res. 5(3): 471-477. 
Schlegel, G. and Schlegel, R. 1989. A compendium of reciprocal intervarietal translocations in hexaploid wheat. Kulturpflanze 37: 163-176.

- and Weryszko, E. 1979. Intergeneric chromosome pairing in different wheat-rye hybrids revealed by the Giemsa banding technique and some implications on karyotype evolution in the genus Secale. Biol. Zbl. 98: 399-407.

Stefanowska, G. 1988. Chromosome pairing in octoploid triticale (Triticosecale Wittmack) depending on the initial wheat Triticum aestivum $\mathrm{L}$.) and rye (Secale cereale L.) cultivars. Genetica Polonica 29: 257-264.

Thomas, J. B. and Kaltsikes, P. J. 1972. Genotypic and cytological influences on the meiosis of hexaploid triticale. Can. J. Cytol. 14: 889-898.

- and -1983 . Effect of chromosomes $1 \mathrm{~B}$ and $6 \mathrm{~B}$ on nucleolus formation in hexaploid triticale. Can. J. Genet. Cytol. 25: 292-297.

Vieira, R., Mello-Sampayo, T., Queiroz, A., Morais, L. and Viegas, W. S. 1991. Chromosome instability in intergeneric hybrids of Triticum aestivum $\times$ tritordeum (amphiploid Hordeum chilense $\times$ Triticum turgidum) with high dosage of $\rho h 1$ gene of wheat. Hereditas 114: 271-276.

Yasumuro, Y., Nakata, N. Kawahito, S. and Sasaki, M. 1987. Nucleocytoplasmic interaction in the seed fertility causing the 2D-2R substitution in hexaploid triticale. Japan J. Breed. 37: 297-404. 